\title{
HTLS Upgrades and Payback for the Economic Operation Improvement of Power Transmission Systems
}

\author{
Askhat Tokombayev Gerald T. Heydt
}

Abstract - The increase of transmission line thermal ratings by reconductoring with High Temperature Low Sag (HTLS) conductors is a comparatively new technology introduced for transmission expansion. A special design permits HTLS conductors to operate at higher temperatures, therefore allowing passage of higher current, and thus increasing the thermal rating of the transmission line. The comparatively high cost of HTLS conductors may be an obstacle to its large scale implementation. This paper evaluates the expenditures for transmission line reconductoring using HTLS, the consequent benefits obtained from the potential decrease in operating cost for thermally limited power transmission systems. Estimates of the "payback period" are used to evaluate the cost effectiveness of reconductoring with HTLS. The evaluation is performed using a 225 bus equivalent of the 2012 summer peak Arizona portion of the Western Electricity Coordinating Council (WECC). The method is offered for transmission expansion analysis in which an economic benefit is calculated to assist in the transmission expansion decision.

Index Terms - High temperature low sag; transmission engineering; optimal dispatch; economic efficiency; payback period.

\section{INTRODUCTION: HIGH TEMPERATURE LOW SAG CONDUCTORS FOR TRANSMISSION EXPANSION}

Transmission expansion and upgrades are among the most important parts of power system evolution. The improvement of transmission assets at certain overhead transmission lines can be used as a means to implement power marketing, and thus accommodate load growth and decrease operating cost. There are several techniques that can be used as methods to increase system available transmission capabilities: new line construction, reconductoring of existing transmission lines using conductors with higher thermal ratings, utilization of alternatives such as high voltage DC and high phase order transmission techniques. Certain conditions such as load growth, construction costs, and right-of-way availability should be considered in each particular case to provide the best solution of the transmission expansion problem. References [1-4] discuss the general problem of transmission expansion with a special focus on the opportunities for power marketing.

Load growth and system economical operation adapted to the load both necessitate searching for an effective way to meet transmission capability requirements with minimum expense. In such conditions, reconductoring with high temperature low sag (HTLS) conductors can become a viable option to increase power delivery to the load. HTLS allows a comparatively high current to pass through the conductor with no violations in sag. The higher current rating raises the thermal limit of the overhead line (typically by a factor of two). The possibility to implement such conductors instead of conventional aluminum core steel reinforced (ACSR) conductors with no concomitant upgrades in towers and insulators makes HTLS conductors a potential option to increase thermal rating of the existing transmission paths. This feature may be important in urban areas where new rights-of-way are difficult to attain. References [5-7] are a small sample of the growing literature of HTLS designs. The general approach in the United States has been to exploit the higher thermal rating mainly to raise the emergency rating of the line. Thus in $N-1$ operation, constraints are (partially) alleviated and the result may be better power marketing opportunities. The degree of improvement in power marketing opportunities depends on the results of a security constrained optimal power flow study which would be used to exploit the improved (lessened) thermal limitations. The capability of HTLS transmission lines to conduct high current leads to high active power losses if the transmission line operates at high temperatures under nominal operating conditions. At present in the United States, the HTLS conductors are not usually operated at high temperatures under normal operating conditions: the increased thermal rating is used primarily during emergencies. Therefore during system normal operation, the losses from HTLS conductors are comparable with typical ASCR conductors. However, the increase of transmission line emergency rating is an obvious advantage which can allow power system operation even for $\mathrm{N}-\mathrm{l}-1$ outage cases.

One advantage of transmission line upgrades with HTLS is the lessened time required for reconductoring. Rapid reconductoring is important when long term circuit outage is inconvenient. Perhaps the most serious disadvantage of HTLS reconductoring is the cost of the conductor itself (e.g., 2 - 6 times higher than comparable ACSR) and this 
may be a considerable fraction of the total project cost for short lines. In terms of power system economic operation and power marketing, the analysis of economic impact is necessary. An important factor in making decisions concerning reconductoring with HTLS is the economic benefit from its implementation. The potential for decrease in system operating cost after HTLS reconductoring can become a key factor in making transmission change decisions. Cost-benefit analysis for each particular HTLS implementation case can give necessary information to make better decisions on transmission expansion.

This paper focuses on the potential decrease of the operating cost through increasing thermal transmission capability of selected transmission lines. The selected transmission circuits are those lines whose thermal ratings present significant limits to the attainment of improved operating cost. Only HTLS is considered in this paper; a true study of when to reconductor and when to upgrade would need to include all transmission upgrade alternatives, however. That is, the transmission planner needs to evaluate all technologies and all constraints to achieve a cost effective decision. In this paper, the focus is solely on upgrade of an existing overhead circuit. That is, new rights-of-way are not considered. The objectivity of transmission upgrades are evaluated by estimating the payback period required to compensate all the expenses for the upgrades. In a real transmission planning environment, all possible designs (including conventional overhead technologies) would need to be evaluated. The methods developed in this paper are focused on thermal upgrades afforded by HTLS technologies. Probabilistic modeling of the system load allows the calculation of the minimum payback period. For these purposes, the model based on Chebyshev's inequality is proposed.

\section{EXPANSION PLANNING VS. POWER SYSTEM OPERATION}

Transmission expansion planning is typically done in the long term, mainly longer than three years with transmission expansion queues often in the five year range [8]. In some cases, upgrade decisions are made in a considerably shorter time horizon because of the reduced requirements of regulatory agencies and land acquisition. However, power system operation, for example security improvement, is done in nearly real time with short term decisions. The time horizons for transmission expansion and power system operation are radically different as are the basic objectives. Nonetheless, transmission expansion planning should include issues and analyses of economic operation, especially when the transmission expansion is in the form of an upgrade to existing facilities.

One incentive for transmission expansion and upgrades may be system operational cost reduction. Load growth uncertainty and system load in general are important factors which should be considered during the transmission expansion planning. Due to uncertainty, error in the power demand forecast can lead to significant deviation from the expected savings resulting from transmission upgrades. Investigation of a method to estimate the shortest payback period obtained from transmission system upgrades is important for the evaluation of the transmission planning overall.

Although the present practice in power engineering is to separate the transmission expansion process from operations, for purposes of the analysis of this paper, the reduction in operating costs is used as a partial justification and cost-to-benefit rationale for transmission upgrades (e.g., [1]). Considering the disparity between the transmission planning and the operation horizons, it is especially important to include the impact of uncertainty.

\section{SECURE OPERATION OF POWER SYSTEMS}

The main operating requirements for power systems are reliability, stability and low operating costs. Secure system operation refers to compliance with $N-1$ contingency requirements which indicates that after the loss of a single generator or transmission asset, the system will operate with no system component outside its nominal operating range. The constrained minimization of operating costs is accomplished using optimal power flow (OPF) study techniques. Transmission expansion and planning occur over a very different time horizon and with different objectives as compared to system operation. Nonetheless, transmission planning and expansion are central to the creation of a bulk system that is capable of secure and economical operation. Compliance with $N-1$ contingency requirements is basic, i.e. the system capability to operate with no violation in bus voltage levels, transmission line thermal ratings or security (stability) constraints after the outage of any single system component. For most transmission systems, adherence to $\mathrm{N}-\mathrm{l}$ requirements makes operation close to thermal ratings difficult. If thermal ratings limit economic dispatch, these thermal ratings may be viewed as a limitation for the improvement of operating cost. References [9-10] describe the cases where generation redispatch is limited by transmission congestion.

It is important to note that in the United States, the usual operating policy relating to operation of HTLS conductors is that these circuits are not operated at their high nominal current ratings. The continuous ampacity ratings of HTLS conductors are typically in the order of twice those of comparable ACSR conductors. Instead of operating 
HTLS conductors at their high current rating, the higher ampacity rating is exploited only for cases of $N$ - 1 outage contingencies. That is, the higher ampacity rating of HTLS is used for emergency cases. This operating policy thereby avoids the high active power loss associated with operation at 'double current'.

The generation dispatch performed according to the security constrained optimal power flow (SCOPF) algorithm [11] gives an economically acceptable solution to the calculation of a constrained OPF. The SCOPF is chosen as a starting point for the evaluation of HTLS cost-benefit analysis. The objective of the problem addressed here is the analysis of the decrease in operating cost by upgrading selected overhead circuits to HTLS technologies.

\section{ECONOMIC OPERATION OF POWER SYSTEMS AND THE CONNECTION TO OVERHEAD CIRCUIT THERMAL RATINGS}

Economic power system operation implies the transmission of necessary power to the load with minimum operating expenses. Optimal dispatch of system generation allows the minimization of the total operating cost. During generation optimal dispatch considering $N-1$ contingency analysis, congested transmission lines can occur. Transmission congestion may be a limiting factor. Increase in thermal ratings of selected transmission lines may alleviate active constraints. The reconductoring of these transmission lines with HTLS may be an attractive option.

To make the transmission system upgrade economically sound, the benefit from its implementation should be estimated. A payback period is used to measure the efficacy of HTLS reconductoring. The shorter the payback period, the better. If the increase in the thermal rating of a limiting transmission line reduces the operating cost, than an estimate of the payback period is the integrated period required to recover the transmission upgrade cost. For power systems, the formulation of the AC OPF is

subject to

$$
\min _{P_{i}} \sum C_{i}\left(P_{i}\right)
$$

$$
\begin{gathered}
P_{i \min } \leq P_{i} \leq P_{i \max } \\
Q_{i \min } \leq Q_{i} \leq Q_{i \max } \\
\left|V_{m \text { min }}\right| \leq\left|V_{m}\right| \leq\left|V_{\text {m max }}\right| \\
\left|P_{\text {line } k}+j Q_{\text {line } k}\right| \leq S_{\text {line } k} \\
\left|\delta_{m}-\delta_{n}\right| \leq \delta_{\text {max. }}
\end{gathered}
$$

where inequalities (1) and (2) represent requirements for active and reactive power generation at all generators $i$, inequality (3) represents bus voltage magnitude limits at any bus $m$, inequality (4) represents requirements for the thermal rating of all lines $k$, and (5) represents maximum voltage angle difference for the adjacent buses. Note that $s_{\text {line } k}$ is the thermal rating of line $k$ [11]. Note that long lines are often phase angle security limited, and short lines are often thermally limited. Either limitation may result in an active constraint for economic dispatch. In this paper, the focus is on thermal limits. Thus (4) is considered to be a salient active constraint. However, it is not possible to delete (5) as a potential limitation: accordingly (5) is retained in the economic dispatch formulation. If a limiting factor of the OPF is (4), the upgrade of the corresponding transmission lines allows an alleviation of those constraints, thereby giving a better solution of the OPF. The difference in per hour operating cost before and after reconductoring is used to estimate reconductoring cost-benefit ratio.

The candidate lines for reconductoring should be identified as set $\Omega$ using a SCOPF technique [12]. This yields a per hour operating cost. Then employing an SCOPF once more allows the violation of one transmission line thermal rating in set $\Omega$ under $N-1$ conditions. If the solution is found with no violation of any transmission line thermal rating, then, at the given system wide loading condition, the system economic optimal operation is possible with no line upgrades (no reconductoring). Otherwise (i.e., violations are found), define those transmission lines in $\Omega$ as candidates for reconductoring and perform reconductoring using HTLS. For purposes of this study, the resulting upgrade in the thermal ratings is by factor of 2. Subsequently, perform an SCOPF again. The process is repeated until there are no further limitations in thermal ratings. After each reconductoring, calculate the per hour generation cost. The process of defining candidate transmission lines for upgrading is shown in Fig. 1. Decrease in operating cost is a key factor for payback period calculation. Assume that the total cost of reconductoring for a certain line is known. Then the payback period can be estimated dividing the expenses for transmission line reconductoring by the decrease in per hour operating cost and load duration time.

Because the load is changing with the time, for practical estimation, a presumed system load curve should be considered. After reconductoring, the full potential of the HTLS conductors may not be exploited over the entire time horizon. Therefore, the load factor and duration of the peak load should also be considered. It is worthy to note that depending on the system load curve, the alleviation in transmission line constraints afforded by HTLS reconductoring can occur during off-peak periods as well. As a result, the system operating is improved even during off-peak. 


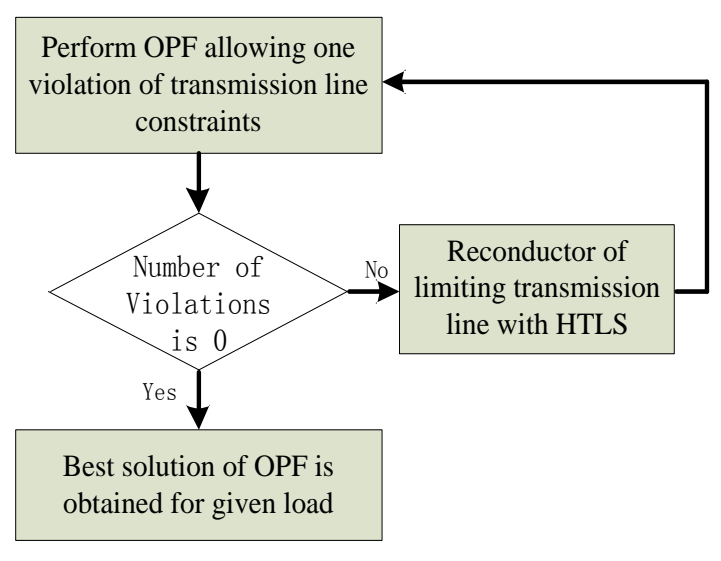

Fig. 1 Basic strategy for the determination of transmission lines to upgrade

The basic advantage of HTLS technology is that these conductors can sustain high current. The losses in the transmission line are directly proportional to the square of the current in the line. As a result, if transmission line is operating under high temperatures, losses increase significantly. For the purposes of identification of circuits that are candidates for reconductoring to HTLS, it is assumed that the HTLS lines are not operating under high temperatures under normal operating conditions. The extra thermal rating is used only during $N-1$ outage events. In addition, in the scope of a large power system, comparatively few lines can be targeted to be reconductored with HTLS. Therefore, during normal operation, the total active power losses in the system increase relatively insignificantly - or not at all if the conductors are not operated at high temperature. The level of individual conductor losses and system wide losses when using HTLS will be explained in the subsequent example provided in Section V. The total cost of the transmission line is calculated using the WECC table of costs for new lines and reconductoring [13].

A quadratic cost approximation was used to estimate the cost of power generation. The cost of generation $P$ at unit $i$ is calculated as

$$
C_{i}=\left(A+B P_{i}+C P_{i}^{2}\right) \times F C+V O \& M \times P_{i}
$$

where $C_{i}$ is total generation cost in $\$ / \mathrm{h}$ at generation unit $i ; P_{i}$ is the power generated at bus $i$ in $\mathrm{MW} ; A, B$ and $C$ are cost coefficients or multipliers; $F C$ is fuel cost and $V O \& M$ is Variable Operations and Maintenance. The value of the multipliers is dependent on the generator type and the multipliers are evaluated using historical data from the generating units.

Dependent on the system topology, when the load is growing on certain buses, transmission system upgrades become necessary. A typical example is a bus load at bus $\mathrm{C}$ supplied by two transmission lines (namely A to C and B to $\mathrm{C}$ ): if an apparent power of the load at $\mathrm{C}$ is higher than the thermal rating of one of the transmission lines, then the requirement to operate normally at an $N-1$ outage case will be violated. In such a case, reconductoring of one of the two supply transmission lines using HTLS does not change the generation dispatch. Therefore, the payback period for reconductoring of such transmission lines under the given fixed load is infinite.

\section{SYSTEM LOADING STATISTICS AND THE USE OF THE CHEBYSHEV INEQUALITY TO IDENTIFY THE CONFIDENCE IN PAYBACK PERIOD CALCULATIONS}

Due to uncertainty in load forecast, the load growth forecast problem is usually represented as a probabilistic model. Application of the probabilistic model based on Chebyshev's inequality may be suitable for the assessment of the economic efficiency obtained after upgrades regardless of the load distribution. Chebyshev's inequality gives an upper bound for the probability that a random variable is greater than a certain value. The advantage of Chebyshev's inequality is the model applicability irrespective of the distribution that random variable. A disadvantage is that the Chebyshev's inequality can only give the upper bound of the cited probability, but not its exact value. In this application, the random variable considered is the system-wide effective peak demand. Let $X$ denote that peak demand. Since the forecasted load usually has unknown probability distribution, the model based on Chebyshev's inequality cannot guarantee the accuracy of the results. Implementation of a proposed model allows the estimation of the shortest expected payback period from a selected transmission upgrade method.

According to Chebyshev [14], for any random variable $X$ with mean value $\mu_{x}$ and variance $\sigma_{x}^{2}$, the following inequality holds, 


$$
P\left\{\left|X-\mu_{x}\right| \geq t\right\} \leq \frac{\sigma_{x}^{2}}{t^{2}}
$$

where $t \geq \sigma_{x}$. The Inequality (7) holds for any probability distribution function. Standardization of the random variable allows setting the mean value of the variable to be zero, and standard deviation to be one (i.e. standardized measure). As a result, (7) can be represented as

$$
P\left\{\left|X^{\prime}\right| \leq t\right\}=P\left\{-t \leq X^{\prime} \leq t\right\} \geq 1-\frac{1}{t^{2}}
$$

where $X^{\prime}=\frac{X-\mu_{x}}{\sigma}$. In terms of the probability density function, Inequality (8) can be expressed as

$$
\int_{-t}^{t} f(x) d x \geq 1-\frac{1}{t^{2}}
$$

Assuming symmetric distribution of the load, that is $\int_{-t}^{0} f(x) d x \approx \int_{0}^{t} f(x) d x$, in terms of probability distribution function, (9) can be expressed as

$$
\begin{aligned}
& F(t) \geq 1-\frac{1}{2 t^{2}}(t \geq 1) \\
& F(-t) \leq \frac{1}{2 t^{2}}(t \geq 1)
\end{aligned}
$$

With reference to (10), Fig. 2 shows the probability distribution function of the random variable which takes the value greater than parameter $t$. The Chebyshev's inequality bounds are shown as dash-dot line. According to Chebyshev's inequality, the probability distribution function curve for any kind of distribution lies between Chebyshev's bounds. That is, the distribution of a random variable $x$ lies below the dash-dot line for $t \leq-1$; and the distribution of $x$ is above the dash-dot line for $t \geq 1$. The dashed line on the plot is a probability distribution function for a normally distributed random variable, and the solid line is for normalized load data (i.e. standardized measure), taken from the actual demand at the PJM interconnection for 2012 (as a representative case, [19]).

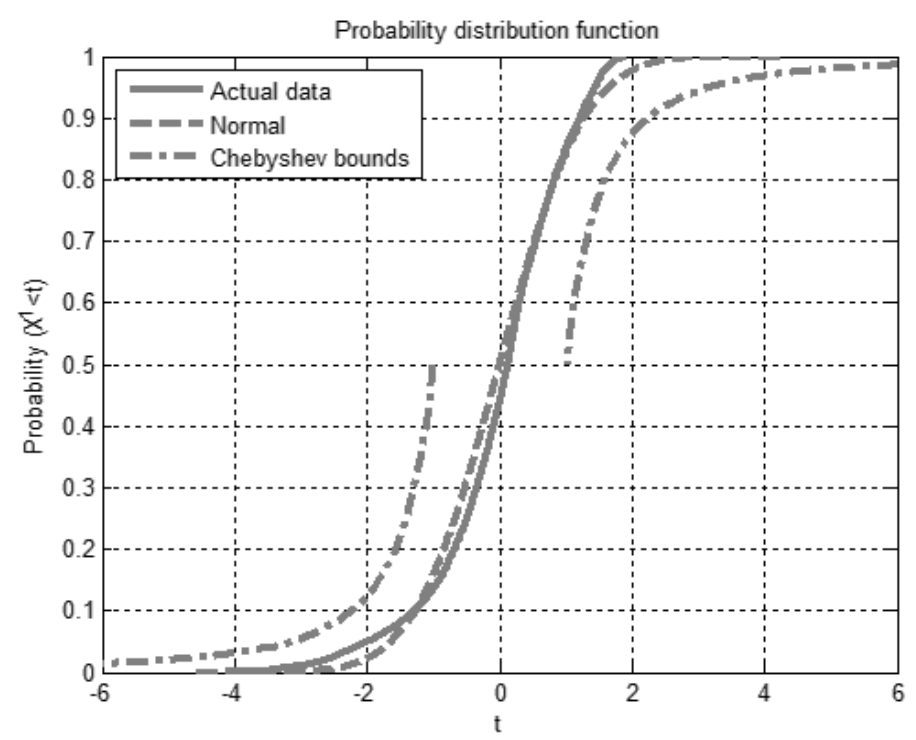

Fig. 2 Probability distribution function illustrating $(10 \mathrm{a}, \mathrm{b})$

The method of expected payback period assessment is used to evaluate the economic effect from transmission upgrades. The operational cost reduction after performing the transmission system upgrades is a function of the load. For a normal distribution of the peak demand, probability density function is known. For Chebyshev's inequality bounds, probability distribution function curve is shown. The probability density function can be found by differentiation of the probability distribution curve.

For a random variable with given probability distribution, the probability distribution curve can be approximated as a piecewise linear function. Let random variable $X$ be the system peak load. The operating cost reduction $c(x)$ at load $X=x$ is a function of $x$. The expectation of the operation cost reduction can be found by 


$$
\int_{-\infty}^{\infty} c(x) f(x) d x=\left.c(x) F(x)\right|_{-\infty} ^{\infty}-\int_{-\infty}^{\infty} F(x) d c(x)
$$

The system operation cost increases with the load. Therefore, the higher the system load, the higher the cost reduction after performing transmission upgrades. The expectation of system operation cost reduction calculated using Chebyshev's inequality gives the highest cost reduction, i.e. the expected time for payback period is lowest. Therefore, the expected payback period assuming the Chebyshev's inequality bounds can be used as a reference for the shortest expected payback period from the transmission upgrades.

\section{CASE STUDY: AN EXAMPLE OF APPLICATION}

The 225 bus Arizona portion of the WECC system was used as a test bed to analyze the effectiveness of HTLS reconductoring. References [17-18] describe typical ratings for a range of different HTLS conductors. The ratings of the conductor denominated as Aluminum Conductor Composite Reinforced (ACCR) was used for this study as typical [17]. The 2012 summer peak load case was used as a base case with some system data "tuning" to insure that the base case is $N-1$ compliant. The data tuning was needed to avoid inaccuracy due to the equivalency of the actual southwest WECC system (e.g. equivalence of circuits below $115 \mathrm{kV}$, and omission of certain out-of-area interconnections). The base case studied was a reduced load case to insure $N-1$ compliance. A load growth study was performed to evaluate the reasonableness of HTLS implementation. No solutions other than HTLS upgrades are considered. No detail of the dynamic stability of the resultant system was considered except that the steady state line voltage phase angle differences were constrained to $30^{\circ}$. The simulation was performed using PowerWorld software. The values of the generation cost multipliers in (6) are shown in Table I [15]. For the reconductoring of those transmission lines which do not improve the solution of the SCOPF, assume that there is no payback. Such lines are not considered further.

TABLE I COST FUNCTION COEFFICIENTS FOR DIFFERENT GENERATION TYPES
\begin{tabular}{|c||c|c|c|c|c|}
\hline $\begin{array}{c}\text { Generation } \\
\text { Type }\end{array}$ & $A$ & $B$ & $C$ & $\begin{array}{c}\text { Fuel cost } \\
(\$ / \mathrm{Mbtu})\end{array}$ & $\begin{array}{c}\text { VO\&M } \\
(\$ / \mathrm{MWh})\end{array}$ \\
\hline \hline Coal fired & 0 & 20 & 0.01 & 4.945 & 1.442 \\
\hline Nuclear & 0 & 20 & 0.01 & 1.286 & 2.285 \\
\hline $\begin{array}{c}\text { Natural Gas } \\
\text { (Gas Turbine) }\end{array}$ & 0 & 12.17 & 0.01 & 6.062 & 2.357 \\
\hline $\begin{array}{c}\text { Natural Gas } \\
\text { (Steam Turbine) }\end{array}$ & 0 & 11.27 & 0.01 & 6.072 & 1.195 \\
\hline $\begin{array}{c}\text { Natural Gas } \\
\text { (Combined Cycle) }\end{array}$ & 0 & 12.193 & 0.01 & 6.062 & 0.827 \\
\hline Hydro & 0 & 10 & 0 & 1.00 & 1.287 \\
\hline
\end{tabular}

According to the method discussed in Section III, the security constrained optimal power flow was performed allowing the violation in thermal rating of only one line, and estimation of the decrease in operating cost after performing transmission line reconductoring. The decrease in operating cost, reconductoring cost and payback period for operation at the peak load period is shown in Table II. In Table II, the transmission line bus names (e.g. YVP, VRD) are the identified line terminals for reconductoring. The bus names are masked to protect proprietary interests; however, the line lengths are reasonably accurate as obtained from a detailed study using Google Earth. In Table II, the payback period is estimated assuming permanent operation at the peak load conditions. This point is considered further below.

In this study, reconductoring of transmission lines is performed when one of the lines becomes congested during $\mathrm{N}-1$ contingency analysis, i.e. operates at $100 \%$ of its long term thermal rating. Test cases indicate that for a large scale system, upgrade of only one line does not change generation dispatch significantly. As a result, the impact from the reconductoring is low and the payback period is long. If one considers load growth, the impact from reconductoring may become significant. Reductions in operating cost and payback period at higher load levels for the indicated WECC test bed are shown in Table III. Note in Table III that the peak load period is accounted as either the full day $(24 \mathrm{~h}$ ) or a fraction of a day (namely $2 \mathrm{~h}$ for this study): this calculation is shown in the rows of the table separated by the solidus (i.e., a slash, /). A typical transmission line life is 35-40 years [16]. Assuming that the peak load of the system is only two hours per day, the economic benefit becomes evident from Table III. The benefits from decreased operating cost at non-peak load conditions are not considered. However, decrease in operating cost at non-peak load periods can reduce the payback period further than those indicated in Table III. 
TABLE II TRANSMISSION LINE RECONDUCTORING COST, REDUCTION IN OPERATING COST AND ESTIMATED PAYBACK PERIOD

\begin{tabular}{|c|c|c|c|c|c|}
\hline $\begin{array}{c}\text { Fraction of } \\
\text { total load in the } \\
\text { base case }\end{array}$ & $\begin{array}{l}\text { Transmission line } \\
\text { (voltage level) }\end{array}$ & $\begin{array}{c}\text { Possible to } \\
\text { avoid line } \\
\text { overloading by } \\
\text { suboptimal } \\
\text { redispatch }\end{array}$ & $\begin{array}{c}\text { HTLS } \\
\text { reconductoring } \\
\text { cost } \\
\left(10^{6} \$\right)\end{array}$ & $\begin{array}{c}\text { Reduction } \\
\text { in operating } \\
\text { cost } \\
\text { (\$/hour) }\end{array}$ & $\begin{array}{c}\text { Payback } \\
\text { period } \\
\text { (years) }\end{array}$ \\
\hline 10.09 & YVP -VRD (230 kV) & No & 45.82 & - & - \\
\hline 10.77 & APC - ADM $(115 \mathrm{kV})$ & No & - & - & - \\
\hline 10.87 & LCS - CNT $(230 \mathrm{kV})$ & Yes & 9.811 & 149.48 & 7.492 \\
\hline 11.26 & $\begin{array}{l}\text { TSS- DLS }(115 \mathrm{kV}) \\
\text { CLA -LLP }(230 \mathrm{kV}) \\
\end{array}$ & $\begin{array}{l}\text { No } \\
\text { No }\end{array}$ & $\begin{array}{r}- \\
66.739 \\
\end{array}$ & $\begin{array}{l}- \\
- \\
-\end{array}$ & $\begin{array}{l}- \\
- \\
-\end{array}$ \\
\hline 11.56 & DLC - NLS (115 kV) & No & - & - & - \\
\hline 12.15 & LLP - CCC (230 kV) & No & 61.48 & - & - \\
\hline 12.44 & $\begin{array}{l}\text { SAT - TRS }(230 \mathrm{kV}) \\
\text { AFI - GLL }(230 \mathrm{kV}) \\
\text { RRD - OOE }(230 \mathrm{kV})\end{array}$ & $\begin{array}{l}\text { Yes } \\
\text { Yes } \\
\text { Yes }\end{array}$ & $\begin{array}{l}7.709 \\
3.311 \\
5.045 \\
\end{array}$ & $\begin{array}{l}38.03 \\
52.01 \\
82.96 \\
\end{array}$ & $\begin{array}{l}23.14 \\
7.26 \\
6.94 \\
\end{array}$ \\
\hline 12.54 & MMK - SSL $(230 \mathrm{kV})$ & Yes & 6.937 & 42.87 & 18.47 \\
\hline 13.22 & GLL - GDL $(230 \mathrm{kV})$ & Yes & 2.522 & 9.15 & 31.46 \\
\hline
\end{tabular}

TABLE III RECONDUCTORED TRANSMISSION LINES AND THEIR CORRESPONDING PAYBACK PERIOD

\begin{tabular}{|c|c|c|c|c|c|c|c|c|}
\hline \multirow{2}{*}{\multicolumn{2}{|c|}{ Transmission line }} & \multicolumn{7}{|c|}{ System wide load (GW) } \\
\hline & & 10.87 & 11.26 & 11.55 & 12.44 & 12.54 & 13.22 & 13.91 \\
\hline \multirow{2}{*}{ LCS - CNT } & $\begin{array}{l}\text { Savings } \\
\$ / \text { hour }\end{array}$ & 149.5 & 2351 & 3705 & 5218 & & 31116 & \\
\hline & $\begin{array}{c}\text { Payback period } \\
\text { (years)* }\end{array}$ & $7.49 / 89.9$ & $0.48 / 5.71$ & $0.30 / 3.62$ & $0.22 / 2.58$ & & $\begin{array}{c}0.04 \\
/ 0.432\end{array}$ & \\
\hline \multirow{2}{*}{$\mathrm{SAT}-\mathrm{TRS}$} & $\begin{array}{l}\text { Savings } \\
\$ / \text { hour }\end{array}$ & & & & 38.03 & & 3641 & \\
\hline & $\begin{array}{l}\text { Payback period } \\
\text { (years)* }\end{array}$ & & & & $23.1 / 278$ & & $0.24 / 2.90$ & \\
\hline \multirow{2}{*}{ AFI - GLL } & $\begin{array}{l}\text { Savings } \\
\$ / \text { hour }\end{array}$ & & & & 52.01 & & 9505 & \\
\hline & $\begin{array}{c}\text { Payback period } \\
\text { (years)* }\end{array}$ & & & & $7.3 / 87.2$ & & $0.04 / 0.48$ & \\
\hline \multirow{2}{*}{ RRD - OOE } & $\begin{array}{l}\text { Savings } \\
\$ / \text { hour }\end{array}$ & & & & 82.96 & & 1842 & \\
\hline & $\begin{array}{c}\text { Payback period } \\
\text { (years)* }\end{array}$ & & & & $6.9 / 83.3$ & & $0.31 / 3.74$ & \\
\hline \multirow{2}{*}{ MMK - SSL } & $\begin{array}{l}\text { Savings } \\
\$ / \text { hour }\end{array}$ & & & & & 42.87 & 13736 & 14233 \\
\hline & $\begin{array}{c}\text { Payback period } \\
\text { (years)* }\end{array}$ & & & & & $18.5 / 221.7$ & $0.06 / 0.69$ & $0.06 / 0.67$ \\
\hline \multirow{2}{*}{ GLL - GDL } & $\begin{array}{l}\text { Savings } \\
\$ / \text { hour }\end{array}$ & & & & & & 9.15 & 5816 \\
\hline & $\begin{array}{c}\text { Payback period } \\
\text { (years)* }\end{array}$ & & & & & & $31.5 / 377.5$ & $0.05 / 0.60$ \\
\hline
\end{tabular}

* Payback period estimated in years for (24 hours peak load / 2 hours peak load)

For the studied case, if the load value is lower than $9.7944 \mathrm{GW}$ (i.e. the peak load value in 2012), then there are no violations in transmission line thermal ratings during $\mathrm{N}-1$ contingency analysis and no lines require upgrades. To observe the benefit from reconductoring during non-peak load conditions, consider the following case: assume that the system has no violations at a peak load of $13.22 \mathrm{GW}$. Then with all indicated transmission lines reconductored using HTLS except SAT - TRS, from Table III it can be seen that at the non-peak load of 12.44 GW, a savings of $38.03 \$ / \mathrm{h}$ is realized.

At total system wide load of $10.87 \mathrm{GW}$, during $\mathrm{N}-1$ contingency analysis, the $230 \mathrm{kV}$ LCS - CNT transmission line becomes congested, i.e. runs at $100 \%$ of its 607 MVA long term thermal rating. When the total system load is 13.22 GW, this upgraded transmission line with thermal rating 1214 MVA runs at $51.2 \%$ of its thermal rating. At the worst $N-1$ transmission outage case, the difference in the magnitude of the current in that line is $+2.04 \%$. This infers 
that during the $N-1$ outage case, active power losses in LCS - CNT line increase only by $+4.12 \%$. Note that the $N-1$ outage case cited results are a relatively small increase in system-wide active power losses. And the increase in active power losses is temporary (i.e., during the outage and during the peak demand). The often quoted disadvantage of HTLS, namely increased system active power loses, does not appear to be significant in this case.

\section{EXPECTED PAYBACK PERIOD EVALUATION}

For calculation of the expected payback period, use the function of cost reduction in terms of system load, and system load growth probability density function. Then, the expectation of cost reduction for each upgraded transmission line can be calculated according to,

$$
C R_{i}=\int_{-\infty}^{\infty} c_{i}(x) f(x) d x
$$

where $C R_{i}$ is the expectation of operational cost reduction for the transmission line $i, c_{i}(x)$ is a function of the operational cost reduction after reconductoring in terms of system load, $f(x)$ is a system load probability density function and $x$ is a system wide load. For calculation simplicity, the function of operational cost reduction is expressed as a piecewise linear function. Part of the values can be seen in Table III. For the comparison purposes, three different models of load distribution are used:

- Normal distribution

- Chebyshev's inequality model

- PJM system 2012 year real load distribution model (assuming that the system load probability distribution changes insignificantly in the time horizon under study).

The probability density function for normal probability distribution is often used for comparison purposes. For the Chebyshev inequality and real (actual data) load distribution models, the analytical expression of probability density function is unknown. Therefore, for these two models, (12) can be calculated as,

$$
C R_{i}=\int_{-\infty}^{\infty} c_{i}(x) f(x) d x=\left.c(x) F(x)\right|_{-\infty} ^{\infty}-\int_{-\infty}^{\infty} F(x) d c_{i}(x)
$$

where $F(x)$ is a probability distribution function. For real load distribution model, $F(x)$ is known from the real data, and for Chebyshev's inequality model $F(x)$ can be found according to (10 a) and (10 b).

For the proposed transmission upgrade project, six transmission lines are targeted for reconductoring. The cost reduction is supposed to begin immediately after performing the reconductoring of the first transmission line. Transmission line LCS-CNT becomes reconductored by the end of 2014. Therefore the payback period for the project begins from the year 2014. Since the system load increases gradually, the system operating cost also increases following the system load.

To estimate the payback period of the project, the calculation of the operational cost decrease afforded by each upgraded transmission line is required. Assume that the load growth is equal within two even time periods. Knowing the system peak load of 2012 and 2020, the estimation of the system load during each year during this period is possible. However, the system peak load during each year between 2012 and 2020 is uncertain due to the forecast error. Therefore it (i.e. system peak load) can be handled as a probabilistic model. The system peak load mean values for these years are shown in Tables IV, V and VI.

The calculation of the operational cost reduction allows estimation of expected revenue achieved from the transmission upgrades during these years. For instance, the mean value of system peak load in 2014 is $10.47 \mathrm{GW}$ with $5 \%(0.524 \mathrm{GW})$ standard deviation. Having known probability density function $f(x)$ or probability distribution function $F(x)$ and operational cost decrease $c(x)$, calculation of the expected operational cost reduction for the upgraded lines becomes possible using (13). A sum of the expected operational cost reductions achieved by the upgraded transmission lines (in this case, before 2014 only one transmission line, i.e. LCS - CNT was upgraded) gives the expected system operational cost reduction for 2014. Assume that the system operates at the peak load conditions 2 hours daily (730 hours per year). Then the annual revenue obtained resulting from reconductoring is found by multiplying the expected operational cost reductions by number of hours operated during one year (730 hours). 
Table IV. Expected operational cost reduction and total revenue

(Based on a normal probability distribution load model)

\begin{tabular}{|c|c|c|c|c|c|c|c|c|}
\hline \multicolumn{2}{|c|}{$\begin{array}{c}\text { Time period } \\
\text { (Year) }\end{array}$} & 2014 & 2015 & 2016 & 2017 & 2018 & 2019 & 2020 \\
\hline \multicolumn{2}{|c|}{$\begin{array}{l}\text { Load Mean Value } \\
\text { (GW) }\end{array}$} & 10.47 & 10.81 & 11.14 & 11.49 & 11.82 & 12.16 & 12.5 \\
\hline \multirow{7}{*}{ 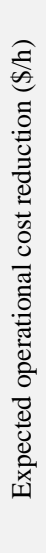 } & LCS - CNT & 619 & 1144 & 1915 & 3262 & 5152 & 8278 & 12810 \\
\hline & SAT - TRS & - & - & - & - & 204 & 556 & 1135 \\
\hline & $\mathrm{AFI}$ - GLL & - & - & - & - & 528 & 1444 & 2956 \\
\hline & $\mathrm{RRD}-\mathrm{OOE}$ & - & - & - & - & 109 & 292 & 590 \\
\hline & MMK - SSL & - & - & - & - & - & - & 3901 \\
\hline & GLL - GDL & - & - & - & - & - & - & 304 \\
\hline & $\begin{array}{c}\text { All upgraded } \\
\text { transmission } \\
\text { lines }\end{array}$ & 619 & 1144 & 1915 & 3262 & 5993 & 10570 & 21696 \\
\hline \multicolumn{2}{|c|}{$\begin{array}{c}\text { Total revenue } \\
\left(10^{6} \$\right)\end{array}$} & 0.452 & 0.835 & 1.398 & 2.381 & 4.375 & 7.716 & 15.838 \\
\hline
\end{tabular}

Table V. Expected operational cost reduction and total revenue

(Based on Chebyshev distribution load model)

\begin{tabular}{|c|c|c|c|c|c|c|c|c|}
\hline \multicolumn{2}{|c|}{$\begin{array}{l}\text { Time period } \\
\text { (Year) }\end{array}$} & 2014 & 2015 & 2016 & 2017 & 2018 & 2019 & 2020 \\
\hline \multicolumn{2}{|c|}{$\begin{array}{c}\text { Load Mean Value } \\
(\mathrm{GW})\end{array}$} & 10.47 & 10.81 & 11.14 & 11.49 & 11.82 & 12.16 & 12.5 \\
\hline \multirow{7}{*}{ 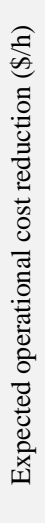 } & $\mathrm{LCS}-\mathrm{CNT}$ & 1918 & 3094 & 3379 & 5225 & 8157 & 13294 & 16875 \\
\hline & SAT - TRS & - & - & - & - & 742 & 1363 & 1790 \\
\hline & $\mathrm{AFI}-\mathrm{GLL}$ & - & - & - & - & 1925 & 2649 & 4672 \\
\hline & RRD - OOE & - & - & - & - & 391 & 697 & 908 \\
\hline & MMK - SSL & - & - & - & - & - & - & 6782 \\
\hline & GLL - GDL & - & - & - & - & - & - & 1119 \\
\hline & $\begin{array}{c}\text { All upgraded } \\
\text { transmission } \\
\text { lines }\end{array}$ & 1918 & 3094 & 3379 & 5225 & 8215 & 18003 & 32146 \\
\hline \multicolumn{2}{|c|}{$\begin{array}{c}\text { Total revenue } \\
\left(10^{6} \$\right)\end{array}$} & 1.40 & 2.259 & 2.467 & 3.814 & 5.997 & 13.142 & 23.466 \\
\hline
\end{tabular}

Similarly, the expected cost reduction and total revenue achieved from the transmission lines upgrades can be calculated for each year: the results for the period 2014-2020 are shown in Table IV (the calculations are based on a normal probability distribution load model), and Table V (calculations based on Chebyshev distribution load model) and Table VI (calculations based on real data distribution load model).

According to the Table III, the total investments for the aforementioned six transmission lines upgrade is equal to 39.82 million dollars. The expected revenue achieved from the transmission upgrades during 2014 to 2019 for different types of load distribution are shown in Tables IV, V and VI. The expected revenue obtained before all the transmission lines become reconductored (2014 - 2019), and the non-recovered part of the investment is the difference between the total investments and revenue achieved during the years $2014-2019$. The results are shown in Table VII.

In the test bed example, assuming that the maximum system mean load is $12.5 \mathrm{GW}$, according to the payback period definition, one simply divides the non-refunded investment by the system operation cost reduction in 2020 to obtain the system operation time to achieve total payback. By adding 6 years (i.e., the years 2014-2019 which are the 
previous years of system operation) to the calculated value, one obtains the total payback period for the proposed transmission upgrade project. The calculated expected project payback period is shown in Table VII. The results in Table VII show that the minimum payback period calculated using Chebyshev's inequality is $16.6 \%$ shorter compared with the payback period calculated using the actual data distribution. However, system load distribution function depends on many factors, i.e. load distribution, generation availability, and climatic factors. The Chebyshev model guarantees that the payback period cannot be shorter than the value calculated using the Chebyshev model irrespective to all these factors.

Table VI. Expected operational cost reduction and total revenue (Based on real distribution load model)

\begin{tabular}{|c|c|c|c|c|c|c|c|c|}
\hline \multicolumn{2}{|c|}{$\begin{array}{l}\text { Time period } \\
\text { (Year) }\end{array}$} & 2014 & 2015 & 2016 & 2017 & 2018 & 2019 & 2020 \\
\hline \multicolumn{2}{|c|}{$\begin{array}{c}\text { Load Mean Value } \\
(\mathrm{GW})\end{array}$} & 10.47 & 10.81 & 11.14 & 11.49 & 11.82 & 12.16 & 12.5 \\
\hline \multirow{7}{*}{ 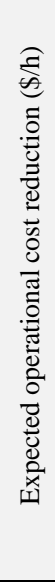 } & $\mathrm{LCS}-\mathrm{CNT}$ & 602 & 1137 & 1794 & 3188 & 5097 & 8155 & 12300 \\
\hline & SAT - TRS & - & - & - & - & 181 & 524 & 1060 \\
\hline & AFI - GLL & - & - & - & - & 469 & 1424 & 2758 \\
\hline & RRD - OOE & - & - & - & - & 165 & 290 & 547 \\
\hline & MMK - SSL & - & - & - & - & - & - & 3573 \\
\hline & GLL - GDL & - & - & - & - & - & - & 446 \\
\hline & $\begin{array}{l}\text { All upgraded } \\
\text { transmission } \\
\text { lines }\end{array}$ & 602 & 1137 & 1794 & 3188 & 5912 & 10383 & 20684 \\
\hline \multicolumn{2}{|c|}{$\begin{array}{c}\text { Total revenue } \\
\left(10^{6} \$\right)\end{array}$} & 0.439 & 0.83 & 1.310 & 2.327 & 4.316 & 7.580 & 15.100 \\
\hline
\end{tabular}

Table VII. Expected operation cost reduction and expected period for the transmission upgrade project

\begin{tabular}{|c|c|c|c|}
\cline { 2 - 4 } \multicolumn{1}{c|}{} & Normal distribution model & Chebyshev model & Actual data distribution \\
\hline $\begin{array}{c}\text { Revenue during } \\
2014-2019\left(10^{6} \$\right)\end{array}$ & 17.155 & 29.079 & 16.802 \\
\hline $\begin{array}{c}\text { Non-refunded } \\
\text { investments }\left(10^{6} \$\right)\end{array}$ & 22.665 & 10.741 & 1.52 years \\
\hline $\begin{array}{c}\text { System operation time } \\
\text { left to achieve total pay- } \\
\text { back }\end{array}$ & 1.43 years & 0.45 years & 7.52 years \\
\hline $\begin{array}{c}\text { Expected project payback } \\
\text { period }\end{array}$ & 7.43 years & 6.45 years & \\
\hline
\end{tabular}

\section{CONCLUSIONS}

This paper suggests a method of identification of transmission lines which should be upgraded using HTLS conductors in compliance with system secure operation requirements. Only upgrades using HTLS are considered and as such, the results are only a benchmark for transmission upgrade assessment.

Implementation of HTLS upgrades may decrease the operating cost of the system. This is a consequence of the alleviation of transmission loading constraints. Reconductoring with HTLS can be reasonable for those cases where the thermal rating of existing transmission lines is a limiting factor of the security constrained optimal power flow. The reasonableness of the reconductoring, estimated as a payback period, varies depending on the system load growth and existing system transmission line loading. If the nominal operation of the transmission system does not utilize the additional ampacity of the HTLS upgrades, there will be no expected increase in transmission losses. This is the usual operating strategy in North America. The higher ampacity ratings of HTLS, under this operating philosophy, are used only for operation during contingencies. 
The upgrade cost of the existing transmission lines using HTLS can be lower than the construction of some types of new transmission lines. The supplementary requirements for HTLS reconductoring are often less intrusive than for other transmission expansion alternatives. The treatment of stability of a system after upgrading transmission circuits was approximate and based on setting a maximum transmission line voltage phase angle difference. If a candidate line is identified for upgrading, a full stability assessment would be required.

The proposed method of calculation of the minimum payback period shows insignificant deviation from the payback period calculated assuming distribution type based on previous years. The advantage of the proposed method is the accuracy of minimum payback period estimation regardless of system load distribution.

\section{REFERENCES}

[1] Dong J., Zhang J., Shi L., 'Evaluation of Transmission Expansion Benefits in Competitive Power Market," Proc. Third International conference on Electric Utility Deregulation and Restructuring and Power Technologies, pp. 1216-1220, 2008.

[2] Fu R., Wei P., Jiang G., Zhou X., Wan Q., Tang G., "New Market Power Driven Multistage Transmission Expansion Strategy in Power Markets," Proc. IEEE Power and Energy Society General Meeting, 2006.

[3] Yu Q., Guo J., Duan X., "Elasticity Modeling for Transmission Network Expansion Planning in Deregulated Power System," Proc. Universities Power Engineering Conference, 2007, pp. 57 - 61.

[4] Shrestha G. B., Fonseka P. A. J., "Congestion-driven Transmission Expansion in Competitive Power Markets," IEEE Transactions on Power Systems, Vol. 19, No. 3, pp.1658 - 1665, 2004.

[5] Gomez Exposito A., Santos, J. R., Romero, P. C., "Planning and Operational Issues Arising From the Widespread Use of HTLS Conductors," IEEE Transactions on Power Systems, Vol. 22, No. 4, pp. 1446-1455, 2007.

[6] Pierre B. J., Heydt G. T., "Increased Ratings of Overhead Transmission Circuits Using HTLS and Compact Designs," Proc. North American Power Symposium, pp. 1 - 6, 2012.

[7] Kopsidas K., Rowland S. M., "A Performance Analysis of Reconductoring an Overhead Line Structure," IEEE Transactions on Power Delivery, Vol. 24, No. 4, pp. 2248 - 2256, 2009.

[8] Osborn D., Lawhorn J., "Midwest ISO Transmission Planning Processes," Proc. IEEE Power \& Energy Society General Meeting, 2009, pp. 1 - 5.

[9] Khanabadi, M., Ghasemi, H., Doostizadeh, M., "Optimal Transmission Switching Considering Voltage Security and N-1 Contingency Analysis," IEEE Transactions on Power Systems, Vol. 28, No. 1, pp. 542-550.

[10] Feng X., Pan J., Le T., Chao H., "Economic Evaluation of Transmission Congestion Relief Based on Power Market Simulations," Proc. IEEE Power Engineering Society General Meeting, Vol. 2, 2003.

[11] Cain, M. B., O’Neil R. P., Castillo A., "History of Optimal Power Flow and Formulations," December 2012, accessed at:

http://www.ferc.gov/industries/electric/indus-act/market-planning/opf-papers/acopf-1-history-formulation-

testing.pdf

[12] Yan P., Sekar A., "A New Approach to Security-Constrained Optimal Power Flow Analysis," Proc. Power Engineering Society Summer Meeting, Vol. 3, pp. 1462-1467, 2001.

[13] Western Electricity Coordinating Council - TEPPC, "Capital Costs for Transmission and Substations - Recommendations for WECC Transmission Expansion Planning," Black and Veatch, 2012.

[14] П. Чебышев (P. Chebyshev), "Des valeurs moyennes," Journal de Mathematiques Pures et Appliquées, v. 2, No. 12, pp. 177 - 184, 1867.

[15] Eftekharnejad S., "The Impact of Increased Penetration of Photovoltaic Generation on Smart Grids," PhD. dissertation, Arizona State University, Tempe AZ, December 2012, p. 61.

[16] Acres International Corporation, "Update of Life-Cycle Cost Studies for Overhead and Underground Electric Transmission Lines - 1996," State of Connecticut, Connecticut Siting Council, Hartford, CT, May 2001.

[17] 3M Company, "3M Aluminum Conductor Composite Reinforced (ACCR) High-Capacity Transmission Conductor," St. Paul, MN, 2014.

[18] American Transmission Company (ATC), "Overhead Transmission Line Ampacity Ratings," Document number CR-0061 v07, April 30, 2014.

[19] PJM Interconnection Hourly Load Data for 2012, Accessed at: http://www.pjm.com/markets-and-operations/energy/real-time/loadhryr.aspx 